\title{
Espécies novas de Blaptica do Rio Grande do Sul, Brasil (Blattaria, Blaberidae, Blaberinae)
}

\author{
Sonia Maria Lopes ${ }^{1} \&$ Edivar Heeren de Oliveira ${ }^{1}$
}

1. Depto de Entomologia, Museu Nacional, Universidade Federal do Rio de Janeiro, Quinta da Boa Vista, São Cristóvão, 20940-040 Rio de Janeiro, Brasil (sonialf@acd.ufrj.br)

ABSTRACT. New species of Blaptica from Rio Grande do Sul, Brazil (Blattaria, Blaberidae, Blaberinae). Five new species of Blaptica Stål, 1875 from Rio Grande do Sul State, Brazil are described and illustrations of Blaptica dubia are presented.

KEYWORDS. New species, Blaptica dubia, taxonomy.

RESUMO. Cinco novas espécies de Blaptica Stål, 1875 do Estado do Rio Grande do Sul, Brasil são descritas e apresentadas ilustrações de Blaptica dubia.

PALAVRAS-CHAVE. Espécies novas, Blaptica dubia, taxonomia.

As baratas pertencentes ao gênero Blaptica Stål, 1875 foram registradas pela primeira vez na Argentina e sua distribuição estende-se até o Brasil, no Estado do Rio Grande do Sul. Apresentam dimorfismo sexual, no qual nos machos as asas são desenvolvidas e nas fêmeas apenas vestigiais. Quanto ao aspecto geral são baratas robustas, de porte avantajado, com comprimento até trinta milímetros.

O gênero Blaptica foi descrito por STÅL (1875) para incluir duas espécies: Blabera bipustulata Thunberg, 1826 e Blabera claraziana Saussure, 1864. Atualmente o gênero reúne cinco espécies.

REHN \& HEBARD (1927) colocaram Blaptica em um dos três grupos que correspondem às linhas de desenvolvimento dos blaberídeos. Princis (1963) confirmou o gênero entre os Blaberinae e McKitTRICK (1964) situou-o na tribo Blaberini.

HePper (1965) enfatizou que a distribuição do gênero é essencialmente neotropical e que as espécies constituem um reservatório de elementos patógenos, portadoras de ectoparasitos e endoparasitos.

Rотн (1970), com base na genitália masculina, aceitou os conceitos de Princis (1963) e McKitTRICK (1964), e situou o gênero num grupo com Archimandrita Saussure, 1893 e Blaberus Serville, 1839, distinguindo Blaptica: (1) pelo ápice do esclerito mediano (L2d) unido ao corpo do mesmo (L2vm); (2) pelo prepúcio que fica em torno do ápice do esclerito mediano como uma membrana flexível com espinhos pequenos, dispostos em uma série múltipla [B. dubia (Serville, 1839), B. pereyrae Hepper, 1965 e B. obscura Saussure \& Zehntner,1894] ou em uma única série (B. interior Hebard, 1921).

Cinco espécies novas de Blaptica do Estado do Rio Grande do Sul são descritas com base na genitália masculina como similares a $B$. dubia, pelos espinhos no prepúcio do esclerito mediano, dispostos em série múltipla.

\section{MATERIAL E MÉTODOS}

O material em parte foi-nos enviado para identificação pelo Dr. Antonio Leite Ruas-Neto, do Instituto de Ciências Biológicas, Universidade de Passo Fundo, Rio Grande do Sul, tendo sido coletado convivendo com Hieroblatta cassidea (Eschscholtz, 1822) espécie pertencente à tribo Monastriini.

Os espécimes foram analisados morfologicamente de acordo com as técnicas utilizadas e descritas em LOPES \& Oliveira (2000) e encontram-se depositados no Museu Nacional, Universidade Federal do Rio de Janeiro (MNRJ).

A designação das peças genitais foi baseada em MCKITTRICK (1964).

Com a finalidade de comparação, foram examinados 20 exemplares de Blaptica dubia do MNRJ, identificados por Isolda Rocha e Silva: ARGENTINA, Entre Rios: Palmar, $2 \sigma^{7}$, 2.XII.1941, Biraben \& Bezzi col.; Isla de Martin Garcia, 우, III.1935, S. R. Castillo col.; Santiago del Estero: Matara, ơ, 12.XII.1939, Biraben col; Salta: Lafayate, ơ, s/data, Biraben col.; Córdoba: Córdoba, ơ, s/data, Berg col.; La Falda, VIII.1963, Magaldi col.; Buenos Aires: Buenos Aires, on, s/data, Ambroscati col.; La Plata, 5 ơ, s/data, J. Tremoleras col.; URUGUAI, Montevideo: Peñarol, ơ, 3.XI.1932, J. Tremoleras col.; Montevideo, + , s/data, Melo Leitão col.; BRASIL, Rio Grande do Sul: X.1971, sem outros dados; Irapuazinho, 2 ㅇ, 4.V.1975, C. Steffen col.; Caçapava do Sul, $\odot$, 30.X.1975, S. Scherer col.; ơ, IX.1957, D. Mendes col.; +, 9.X.1957, D. Mendes col.

\section{Blaptica confusa sp. nov.}

(Figs. 2, 8,14, 20, 27, 28)

Coloração geral castanho-clara, brilhante. Coloração castanho-escura (1) no pronoto: contorno, faixa centro-basal e manchas irregulares, algumas delas em baixo relevo (fig. 8); (2) na cabeça: espaço interocular mais claro em direção à fronte; (3) na região entre e abaixo da base das antenas; (4) na base do clípeo (fig. 2); (5) nas tégminas, no tronco inicial de todas as nervuras; (6) nas 


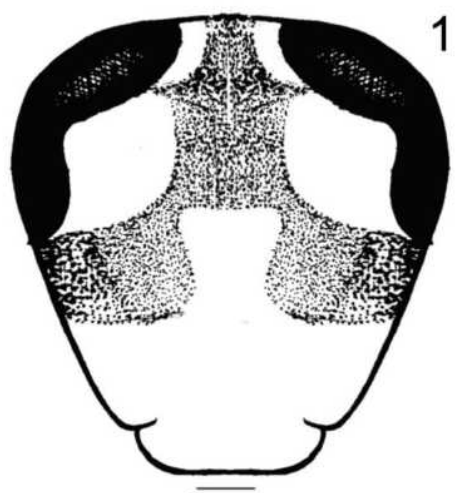

$\overline{1 \mathrm{~mm}}$

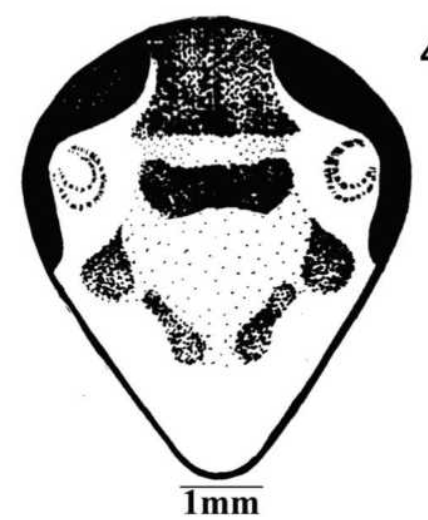

4

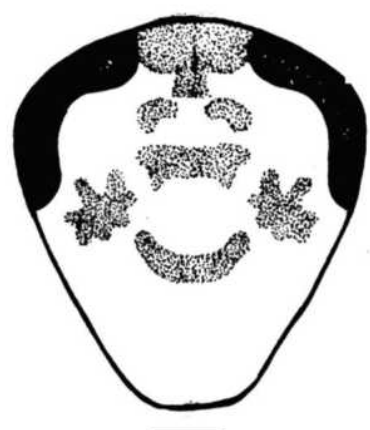

$\overline{1 \mathrm{~mm}}$
2

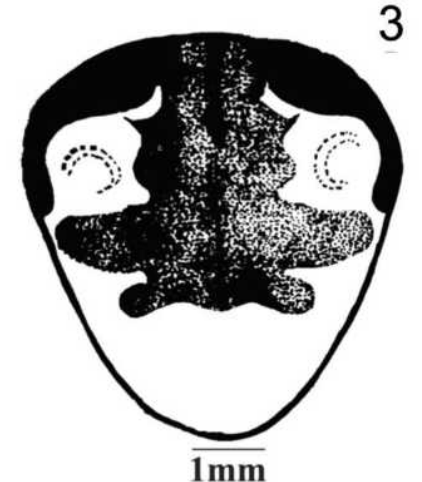

5

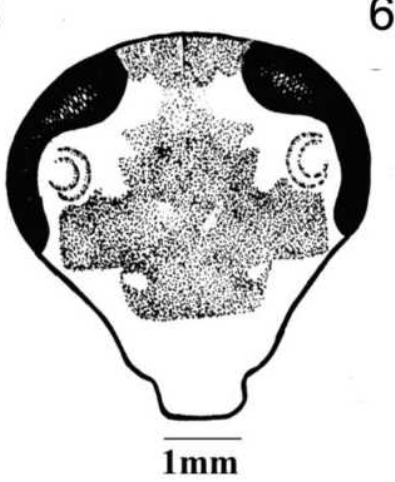

Figs. 1-6. Cabeça (ơ, frontal): 1, Blaptica dubia (Serville, 1839); 2, B. confusa sp. nov.; 3, B. formosa sp. nov.; 4, B. gaucha sp. nov.; 5, B. rothi sp. nov.; 6, B. sulina sp. nov.

pernas: na região dorsal dos fêmures, ápice dos espinhos das tíbias e extremidades das unhas. Palpo maxilar com artículo apical mais escuro e tomentosidade dourada. Olhos negros. Tégminas castanhas nos campos discoidal e anal. Pulvilos esbranquiçados.

Cabeça. Vértice totalmente encoberto pelo pronoto; espaço interocular amplo, medindo cerca de dois terços da área que separa a base das inserções antenais; antenas curtas, não atingindo a metade do abdome; palpos maxilares desenvolvidos, primeiro e segundo artículos pequenos, quarto levemente menor que o terceiro e maior que os dois anteriores, quinto dilatado e tomentoso.

Tórax. Pronoto (fig. 8) elíptico, transverso e convexo, com abas laterais amplas e contorno regular e simétrico. Pernas robustas, coxas largas e fêmures desenvolvidos. Fêmur anterior, na face ântero-ventral, com um a três espinhos pequenos e robustos, espaçados, próximos à base, seguidos em direção ao ápice por pequeninos e finos espinhos, e um espinho apical; face póstero-ventral apenas com um espinho apical. Tíbia anterior curta, medindo cerca da metade do comprimento do fêmur anterior e com uma coroa com seis espinhos grandes ao redor do ápice. Fêmur mediano, na face ânteroventral, com apenas um espinho apical grande; face póstero-ventral com espinhos muito finos, mais concentrados próximo à base e um espinho apical grande. Fêmur posterior semelhante ao fêmur mediano, sem espinho apical na face póstero-ventral. Pulvilos presentes nos quatro artículos tarsais; arólio ausente. Unhas simétricas, simples e desenvolvidas. Tégminas pouco desenvolvidas, não atingindo o ápice do abdome, campo marginal amplo e levemente côncavo; campo escapular curto, campo discoidal amplo e alargado com muitas nervuras transversais, campo anal alargado com nervuras muito próximas umas das outras, com inúmeras nervuras transversais. Asas rudimentares.

Abdome. Placa supra-anal alargada, com reentrância mediana pouco evidenciada e cercos curtos e engrossados. Placa subgenital simétrica, com estilos afilados próximos às bordas da placa. Falômero direito (R2) em forma de gancho, com ápice bastante alargado e recurvado para o interior, com acentuada reentrância na região pré-apical (fig. 20); esclerito mediano (L2vm) alongado, com o ápice (L2d) em forma de sino; prepúcio desenvolvido, com várias projeções de ápices afilados em torno de todo L2d (figs. 27, 28); falômero esquerdo (L1) bastante esclerotizado medianamente, muito desenvolvido (fig. 14).

Medidas, em mm, or. Comprimento total, 33,0; comprimento do pronoto, 9,0; largura do pronoto, 15,0; comprimento da tégmina, 23,0; largura da tégmina, 10,0.

Material-tipo: Holótipo ơ, BRASIL, Rio Grande do Sul: Caçapava do Sul, 30.X.1975, S. Sherer col. (MNRJ).

Etimologia: Do latim confusus, alusivo à dificuldade de ser identificada, devido a semelhança com outras espécies.

Diagnose: Blaptica confusa sp. nov. é semelhante 


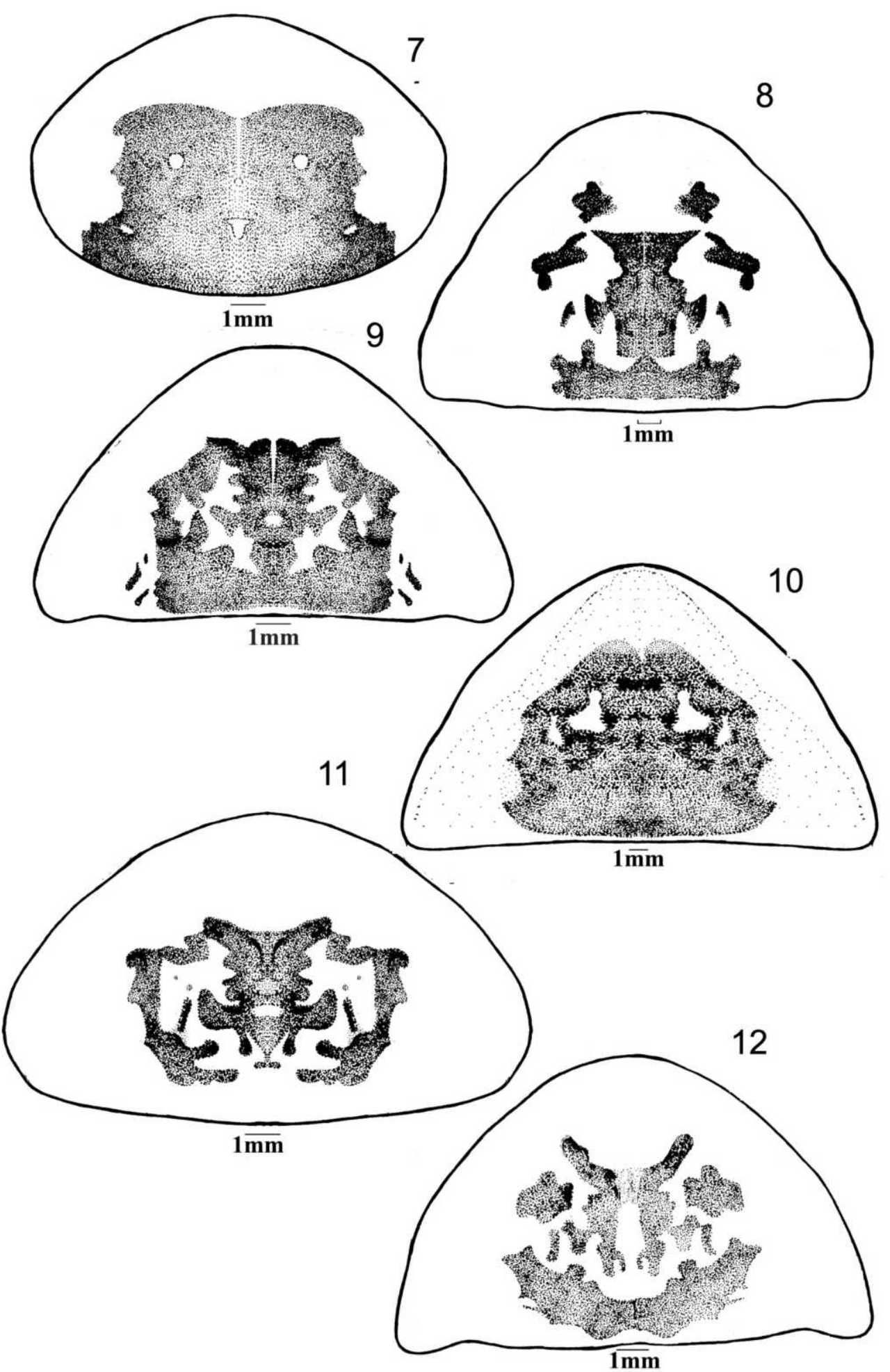

Figs. 7-12. Pronoto (o', dorsal): 7, Blaptica dubia (Serville, 1839); 8, B. confusa sp. nov.; 9, B. formosa sp. nov.; 10, B. gaucha sp. nov.; 11, B. rothi sp. nov.; 12, B. sulina sp. nov.

a $B$. rothi sp. nov. pela coloração do pronoto, diferindo na configuração do ápice (L2d) (figs. 25-28).

Blaptica formosa sp. nov.

(Figs. 3, 9, 15, 21, 29, 30, 37, 38, 39)

Coloração geral castanho-clara brilhante. Coloração castanho-escura (1) no pronoto: em seu contorno e na mancha centro-basal (fig. 9); (2) na cabeça: no vértice; (3) no espaço interocular, (4) na fronte, (5) na base do clípeo (fig. 3), (6) nas antenas, (7) nas pernas: no dorso dos fêmures, base e ápice dos espinhos das tíbias e extremidade das unhas. Pronoto com detalhes em baixo relevo quase negros (fig. 9). Tégmina: tronco inicial de todas 


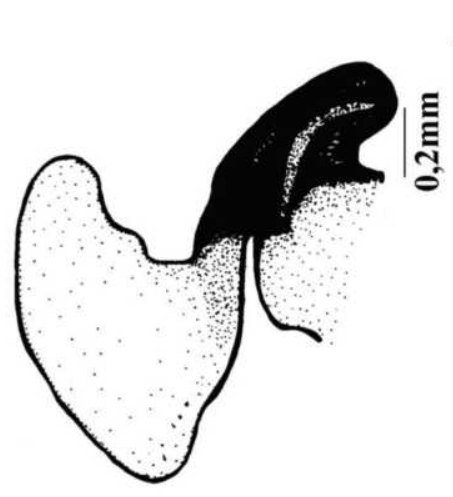

13
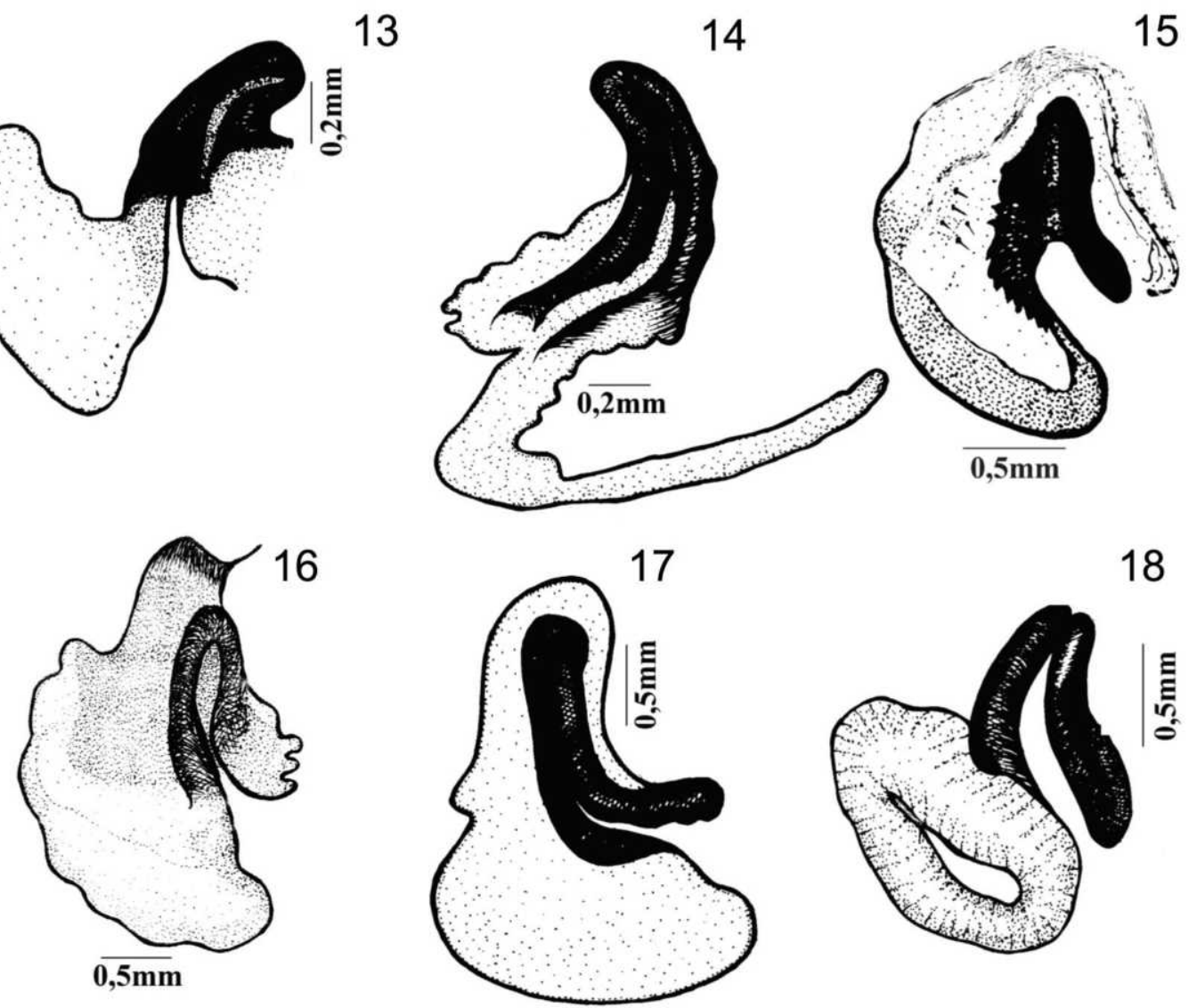

Figs. 13-18. Falômero esquerdo (L1) (ơ, dorsal): 13, Blaptica dubia (Serville, 1839); 14, B. confusa sp. nov.; 15, B. formosa sp. nov.; 16, B. gaucha sp. nov.; 17, B. rothi sp. nov.; 18, B. sulina sp. nov.

as nervuras quase negro, no campo discoidal, mais clara em direção ao campo anal. Olhos acinzentados. Palpos e antenas com tomentosidade dourada. Pulvilos esbranquiçados.

Cabeça. Vértice totalmente encoberto pelo pronoto. Espaço interocular amplo, medindo cerca da metade da área que separa as bases das inserções antenais; antenas curtas, não atingindo a metade do abdome. Palpos maxilares desenvolvidos, primeiro e segundo artículos pequenos, quarto levemente menor que o terceiro, quinto dilatado e tomentoso.

Tórax. Pronoto elíptico, transverso e convexo, com mancha centro-basal simétrica e irregular, abas laterais amplas, contorno regular e simétrico. Pernas robustas e desenvolvidas; coxas largas e fêmures desenvolvidos; fêmur I, na face ântero-ventral, com um a três espinhos pequenos e robustos, seguido de uma série de espinhos pequenos e finos, muito próximos uns dos outros e um apical desenvolvido; face póstero-ventral com um espinho pequeno e robusto no terço apical e um espinho robusto e desenvolvido apical. Tíbia I curta, medindo cerca da metade do comprimento do fêmur I, ao redor de seu ápice com uma coroa composta de seis espinhos desenvolvidos e robustos. Fêmur II com espinhos finos, ciliformes e um apical robusto, em ambas as faces ventrais, face póstero-ventral com espinhos ciliformes em quantidade bem maior próximo à base. Fêmur III semelhante ao fêmur II, sem espinho apical na face póstero-ventral. Pulvilos presentes nos quatro artículos tarsais; arólios ausentes; unhas simétricas, simples e desenvolvidas. Tégminas pouco desenvolvidas, não atingindo o ápice do abdome; campo marginal amplo, alargado e levemente côncavo; campo escapular curto e estreito; campo discoidal amplo e alargado, apresentando muitas nervuras transversais; campo anal desenvolvido com inúmeras nervuras transversais. Asas rudimentares.

Abdome. Placa supra-anal alargada, sem reentrância mediana evidenciada e com cercos curtos e engrossados. Placa subgenital simétrica com estilos afilados próximos à borda da placa. Falômero direito (R2) em gancho, com ápice alargado e recurvado para o interior (fig. 21); esclerito mediano alongado, com o ápice (L2d) retorcido (figs. 29, 30); falômero esquerdo desenvolvido, região mediana esclerotizada com a borda franjada (fig. 15).

A fêmea difere do macho (1) pelo comprimento maior; (2) pela placa supra-anal com cercos curtos e sem segmentação (fig. 37); (3) pela placa subgenital oblonga (fig. 38). (4) pelas válvulas diferenciadas sendo o terceiro par com cílios dispersos e o segundo par afilado (fig. 39).

Medidas, em mm, olo. Comprimento total, 30,0/35,0; comprimento do pronoto, 9,0/11,0; comprimento da tégmina, 20,0/12,0; largura do pronoto, 14,0/18,0; largura da tégmina, 10,0/10,0.

Material-tipo. Holótipo ơ , BRASIL, Rio Grande do Sul:

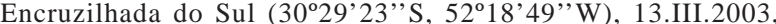
A. L. Ruas-Neto col.; parátipo + , dados iguais ao holótipo (MNRJ). 

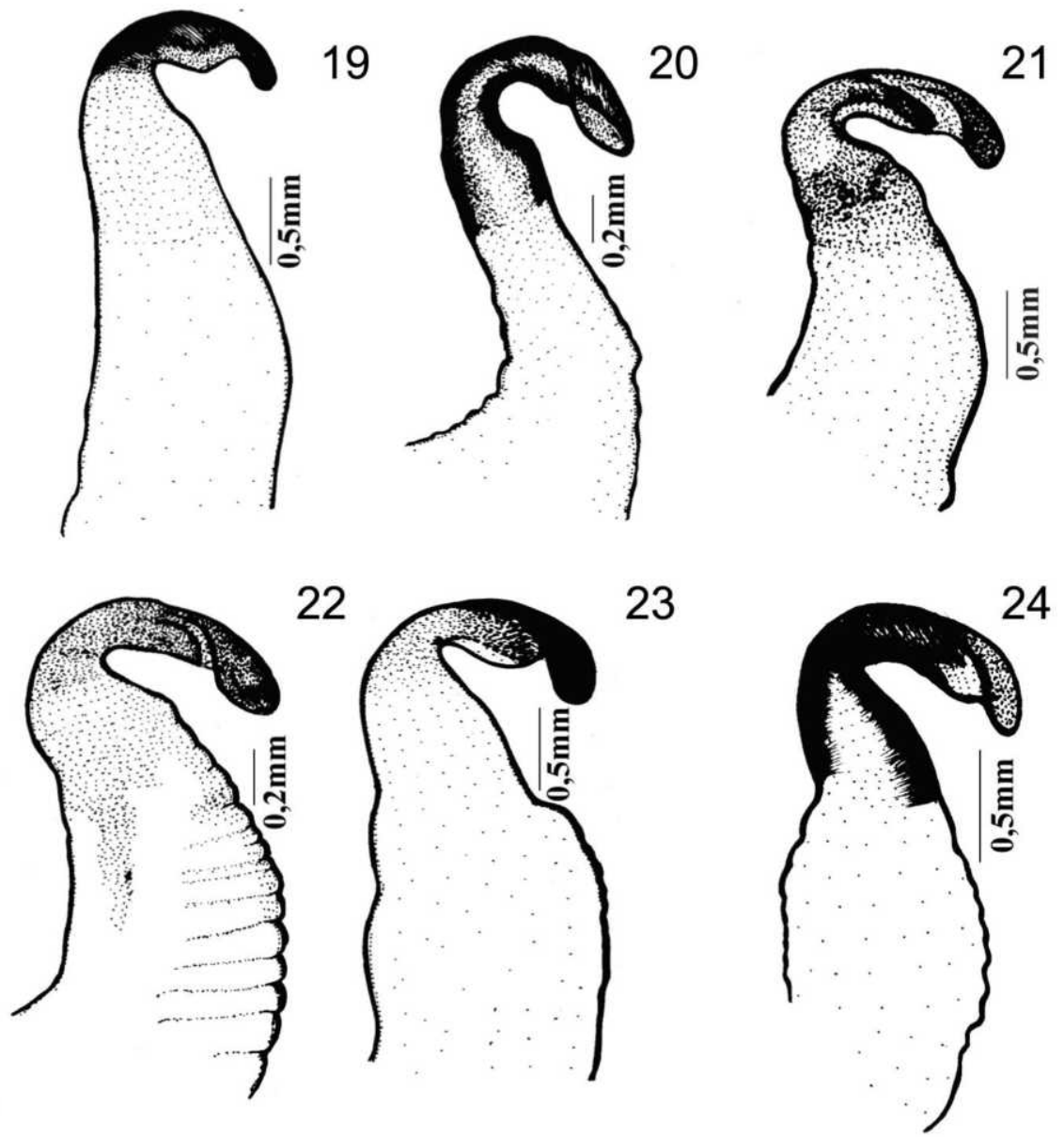

Figs. 19-24. Falômero direito (R2) (ơ, dorsal): 19, Blaptica dubia (Serville, 1839); 20, B. confusa sp. nov.; 21, B. formosa sp. nov.; 22, B. gaucha sp. nov.; 23, B. rothi sp. nov.; 24, B. sulina sp. nov.

Etimologia: Do latim, formosus.

Diagnose: Blaptica formosa sp. nov. difere de $B$. dubia (Serville, 1839) pela configuração do prepúcio em volta do ápice do esclerito mediano (L2d) (figs. 25, 26, 29, 30) e pela configuração do falômero esquerdo (L1) (figs. 13, 15) e do falômero direito (R2) (figs. 19, 21).

\section{Blaptica gaucha sp. nov.}

(Figs. 4, 10, 16, 22, 31, 32)

Coloração geral castanho-clara brilhante. Coloração castanho-escura: (1) no pronoto: em mancha centrobasal, em pontos nele distribuídos e contorno (fig. 10); (2) na cabeça: pelas manchas distribuídas entre os olhos e entre e abaixo das antenas (fig. 4); (3) na tégmina: campo marginal, parte do campo escapular e base do campo anal e nas demais áreas; (4) nas pernas: base e ápice dos espinhos e unhas; (5) na metade apical dos esternitos; (6) nos tergitos abdominais. Pronoto com duas áreas mais claras em seu interior. Olhos negros, com contorno dourado. Tégmina bicolor e tronco inicial de todas as nervuras quase negro. Abdome em cada extremidade lateral dos tergitos com uma mancha, em baixo relevo, negra pequena e circular, seguida de uma mancha arredondada amarelada, mais externa; esternitos bicolores com área amarelada limitada pelo contorno mais escurecido.
Cabeça. Vértice totalmente encoberto pelo pronoto, espaço interocular amplo, medindo pouco mais da metade da área que separa a base das inserções antenais. Palpos maxilares desenvolvidos, sendo o primeiro e segundo artículos pequenos, o terceiro maior que os demais e o ápice do quarto e o quinto dilatados, sendo este tomentoso.

Tórax. Pronoto elíptico, transverso e convexo, com abas laterais amplas, de contorno regular e simétrico. Pernas robustas; coxas largas e fêmures desenvolvidos. Fêmur anterior, na face ântero-ventral, com um a três espinhos pequenos e robustos próximos à base, seguidos até o ápice por uma série de espinhos pequenos e muito finos, terminando por um apical pequeno e robusto; face póstero-ventral com dois espinhos, um pré-apical e outro apical, ambos pequenos e robustos. Tíbia anterior curta, ápice com uma coroa de seis espinhos robustos. Fêmur médio, na face ântero-ventral, com dois a três espinhos pequenos e muito finos espaçados e um apical pequeno e robusto; face póstero-ventral com espinhos espaçados, mais um apical pequeno e robusto. Fêmur posterior, na face ântero-ventral, somente com um espinho apical pequeno e robusto; face póstero-ventral com uma série de espinhos muito finos, da base ao ápice, e um espinho apical pequeno e robusto. Tarsos desenvolvidos; pulvilos presentes em todos os artículos do tarso; arólios 


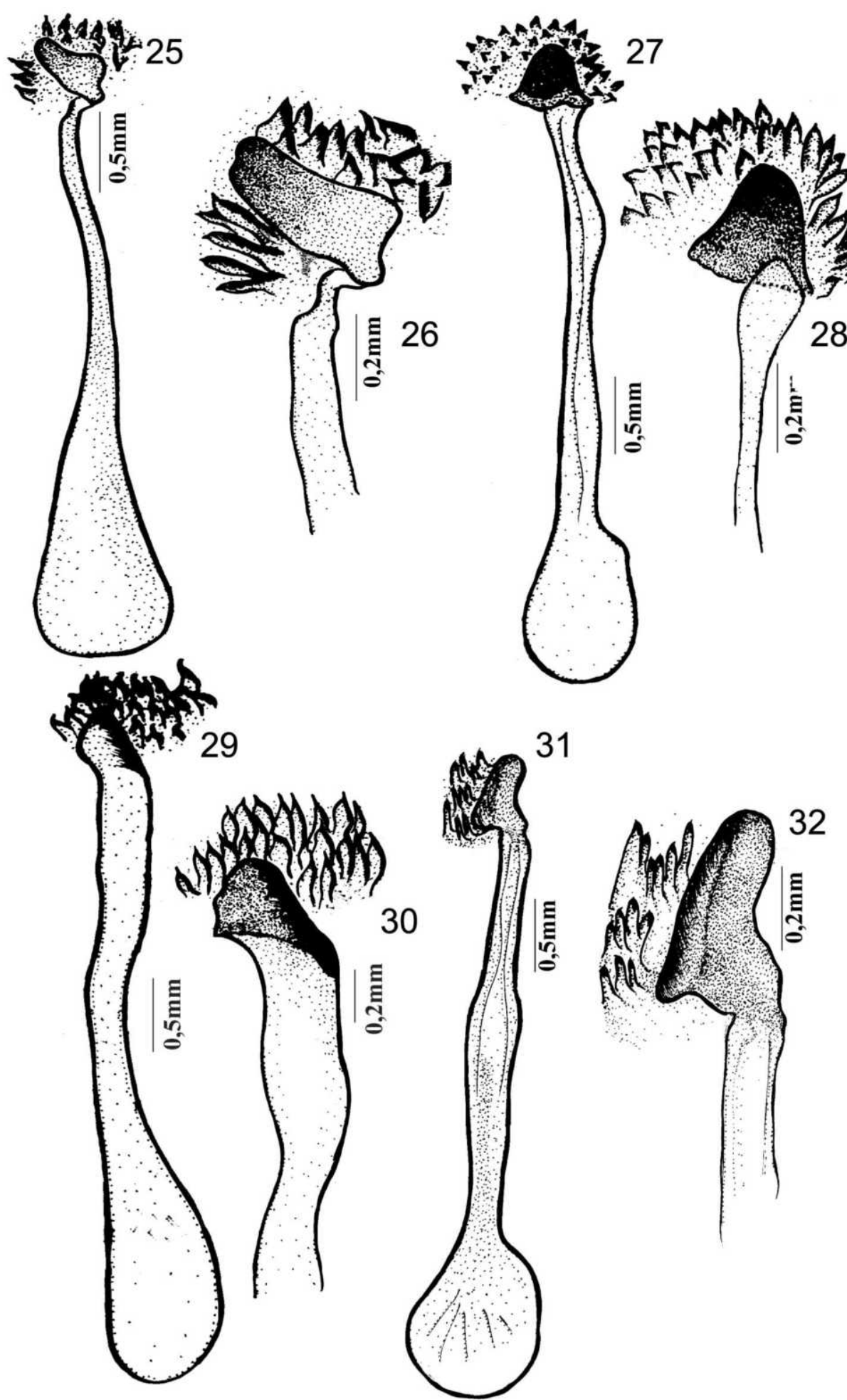

Figs. 25-32. Esclerito mediano (L2vm) e ápice do esclerito mediano (L2d) (o', dorsal), respectivamente: 25, 26, Blaptica dubia (Serville, 1839); 27, 28, B. confusa sp. nov.; 29, 30, B. formosa sp. nov.; 31, 32, B. gaucha sp. nov.

ausentes; unhas desenvolvidas simples e simétricas. Tégminas pouco desenvolvidas, não atingindo o ápice do abdome; campo marginal amplo e levemente côncavo, campo escapular curto e estreito; campo discoidal amplo, alargado com muitas nervuras transversais; campo anal com nervuras muito próximas umas das outras com inúmeras nervuras transversais. Asas rudimentares.
Abdome. Placa supra-anal alargada, com reentrância mediana pouco evidenciada e cercos curtos e engrossados. Placa subgenital simétrica, com estilos afilados próximos às bordas da placa. Falômero direito (R2) em forma de gancho, com ápice alargado e recurvado para o interior e o corpo segmentado (fig. 22); esclerito mediano alongado; prepúcio, lateralmente ao ápice do 
esclerito mediano (L2d), com projeções reunidas em forma de espinhos (figs. 31, 32); falômero esquerdo (L1) pouco desenvolvido, medianamente esclerotizado (fig. 16).

Medidas, em mm, or. Comprimento total, 29,0; comprimento do pronoto, 9,0; largura do pronoto, 15,0; comprimento da tégmina, 18,0; largura da tégmina, 10,0.

Material-tipo. Holótipo ơ, BRASIL, Rio Grande do Sul: Cachoeira do Sul, Irapuazinho (minas), 04.V.1975, C. Steffen col. (MNRJ).

Etimologia: O nome da espécie é alusivo à região onde foi coletado o exemplar.

Diagnose: Blaptica gaucha sp. nov. é similar a $B$. dubia, diferindo pela coloração da cabeça (figs. 1, 4), pela disposição unilateral dos espinhos no prepúcio (figs. $25,26,31,32)$.

\section{Blaptica rothi sp. nov. \\ (Figs. 5, 11, 17, 23, 33, 34)}

Coloração geral castanho-clara brilhante. Coloração castanho-escura: (1) no pronoto: na mancha centro-basal, em detalhes em baixo relevo (fig. 11); (2) na cabeça: manchas no vértice e manchas na fronte, entre e abaixo da base de inserção das antenas (fig. 5); (3) na tégmina: tronco inicial de todas as nervuras e no campo discoidal; (4) nas pernas: região dorsal dos fêmures, ápice dos espinhos das tíbias e extremidade das unhas. Palpos com tomentosidade dourada. Pulvilos esbranquiçados.

Cabeça. Vértice totalmente encoberto pelo pronoto; espaço interocular amplo, medindo cerca de dois terços da área que separa as bases das inserções antenais; antenas curtas, não atingindo a metade do abdome; palpos maxilares desenvolvidos, primeiro e segundo artículos pequenos, quarto levemente menor que o terceiro e maior que os dois anteriores, quinto dilatado e bastante tomentoso.

Tórax. Pronoto elíptico, transverso e convexo, com abas laterais amplas, contorno regular e simétrico. Pernas robustas, coxas largas e fêmures desenvolvidos. Fêmur anterior: face ântero-ventral com um a três espinhos pequenos e robustos próximo à base, seguindo até o ápice por um série de pequenos e finos espinhos, muito próximos uns aos outros, terminando por um apical maior e mais forte; face póstero-ventral com dois ou três espinhos muito finos e espaçados, um espinho robusto, porém muito pequeno, no terço apical e um apical forte, precedido de um espinho menor. Tíbia anterior curta, medindo cerca da metade do comprimento do fêmur anterior e com uma coroa composta de seis espinhos grandes e fortes ao redor do seu ápice. Fêmur mediano com espinhos finos, ciliformes e um apical robusto, em ambas as faces ventrais; face póstero-ventral com espinhos ciliformes próximo à base. Fêmur posterior semelhante ao fêmur mediano, sem espinho apical na face póstero-ventral. Pulvilos presentes nos quatro artículos do tarso; arólios ausentes; unhas simétricas, simples e desenvolvidas. Tégminas pouco desenvolvidas, não atingindo o ápice do abdome, campo marginal bastante amplo e levemente côncavo; campo escapular curto e estreito; campo discoidal amplo e alargado com muitas nervuras transversais;
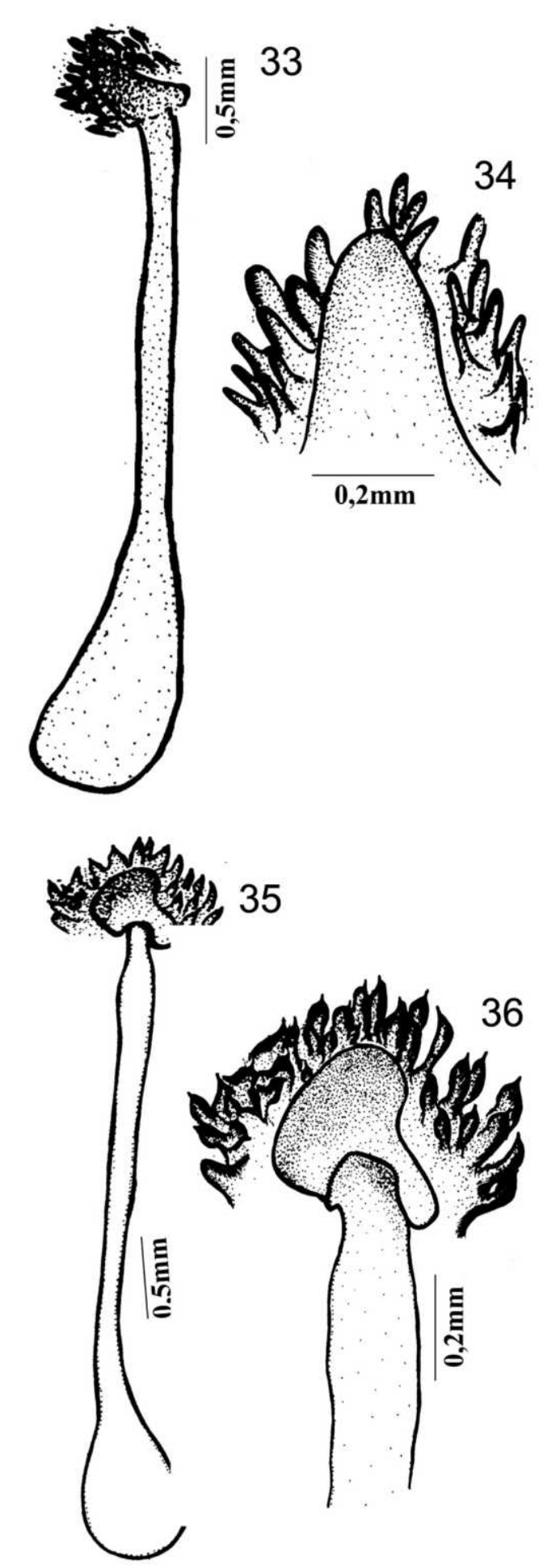

Figs. 33-36. Esclerito mediano (L2vm) e ápice do esclerito mediano (L2d) ( $\overbrace{}^{2}$, dorsal), respectivamente: 33,34 , Blaptica rothi sp. nov.; 35, 36, B. sulina sp. nov.

campo anal desenvolvido, com nervuras muito próximas umas das outras, com inúmeras nervuras transversais. Asas rudimentares.

Abdome. Placa supra-anal alargada, com reentrância mediana pouco evidenciada e cercos curtos e engrossados. Placa subgenital simétrica, com estilos afilados pouco desenvolvidos, próximos à borda da 
placa. Falômero direito (R2) em gancho, com ápice alargado e recurvado para o interior com acentuada proeminência na região pré-apical (fig. 23); esclerito mediano (L2vm) alongado com o ápice (L2d) em forma de um sino; prepúcio desenvolvido, com várias projeções apicalmente arredondadas em diversas fileiras em torno do ápice do esclerito mediano (L2d) (figs. 33, 34); falômero esquerdo (L1) esclerotizado e medianamente muito desenvolvido (fig. 17).

Medidas, em mm, ơ. Comprimento total, 27,0; comprimento do pronoto, 9,0; largura do pronoto, 14,5; comprimento da tégmina, 19,0; largura da tégmina, 10,0.

Material-tipo. Holótipo $0^{7}$. BRASIL, Rio Grande do Sul: Cachoeira do Sul, Irapuazinho, 04.V.1975, C. Steffen col. (MNRJ),

Etimologia: Nome em homenagem póstuma ao Dr. Louis M. Roth, pesquisador de Blattaria da Harvard University, Cambridge, EUA.

Diagnose: Blaptica rothi sp. nov. difere de $B$. dubia (figs. 25, 26; 33, 34) pela configuração do ápice do esclerito mediano (L2d).

\section{Blaptica sulina sp. nov.}

(Figs. 6, 12, 18, 24, 35, 36)

Coloração geral castanho-clara, brilhante. Coloração castanho-escura (1) no pronoto: em mancha centro-basal com detalhes em baixo relevo e contorno (fig. 12); (2) na cabeça: vértice; na área que vai da fronte à base do clípeo, estendendo-se lateralmente na área logo abaixo às bases das inserções antenais (fig. 6); (3) na tégmina: tronco inicial de todas as nervuras, nas nervuras dos campos discoidal e anal; (4) nas pernas: a base dos espinhos, dorso dos artículos tarsais e extremidade das unhas. Espaço interocular e olhos negros com intervalos ou falhas mais claros. Pulvilos mais claros.

Cabeça. Vértice totalmente encoberto pelo pronoto, espaço interocular amplo, medindo cerca da metade da área que separa a base das inserções antenais; antenas curtas não atingindo a metade do abdome; palpos maxilares desenvolvidos, primeiro e segundo artículos pequenos, quarto artículo levemente menor que o terceiro e maior que os anteriores, quinto dilatado e bastante tomentoso.

Tórax. Pronoto elíptico, transverso e convexo, com abas laterais amplas, contorno regular e simétrico (fig. 12). Fêmur robusto nas pernas anteriores. Face ântero-ventral com um a três espinhos médios e robustos próximos à base, seguindo até o ápice por uma série de pequenos e finos espinhos muito próximos uns aos outros e um apical pouco maior; face póstero-ventral com dois a três espinhos muito finos e espaçados, um espinho médio e robusto no terço apical, terminando por um espinho apical pouco maior que o anterior. Tíbia anterior curta, medindo cerca da metade do comprimento do fêmur anterior apresentando ao redor de seu ápice, uma coroa composta de seis espinhos grandes e fortes. Fêmur médio com espinhos finos, ciliformes e um apical robusto, em ambas as faces ventrais; face póstero-ventral com uma série de espinhos ciliformes em maior concentração próximo à base do fêmur. Fêmur posterior semelhante ao médio, não apresentando espinho apical na face póstero-ventral. Pulvilos presentes nos quatro artículos tarsais; arólios ausentes; unhas simétricas, simples e desenvolvidas. Tégminas pouco desenvolvidas, não atingindo o ápice do abdome, campo marginal amplo, alongado e levemente côncavo; campo escapular curto e estreito; campo discoidal amplo e alargado, com muitas nervuras transversais; campo anal desenvolvido com nervuras muito próximas uma das outras, com inúmeras nervuras transversais. Asas rudimentares.

Abdome. Placa supra-anal alargada com reentrância mediana pouco evidenciada e cercos curtos e engrossados. Placa subgenital simétrica, com estilos afilados próximos às bordas da placa. Falômero direito (R2) em forma de gancho, com ápice alargado e recurvado
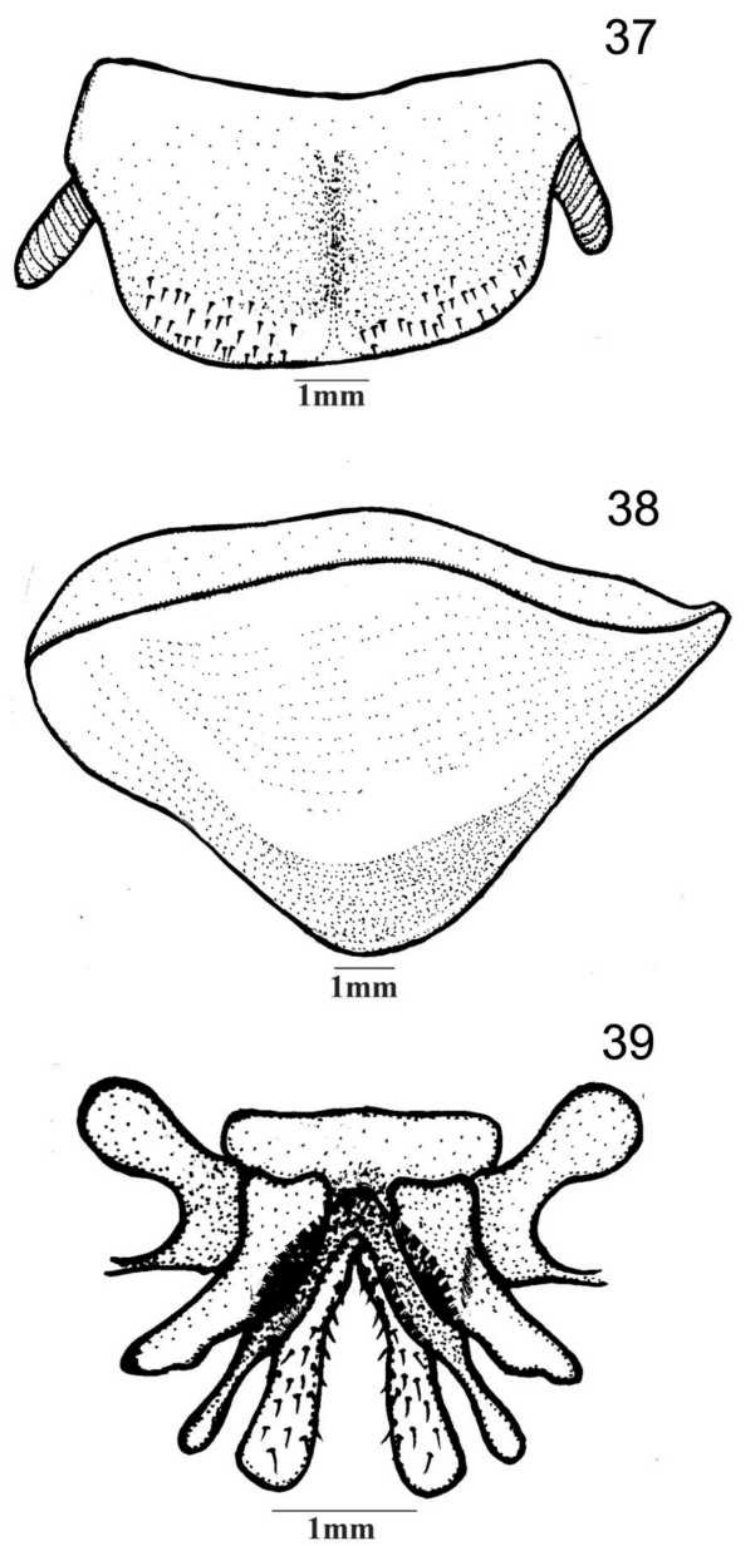

Figs. 37-39. Blaptica formosa sp. nov. (): 37, placa supra-anal, dorsal; 38, placa subgenital, ventral; 39, válvulas, dorsal. 
para o interior dilatado pré-apicalmente (fig. 24); esclerito mediano alongado, com o ápice (L2d) alargado (fig. 35 e 36); falômero esquerdo (L1) desenvolvido, medianamente esclerotizado (fig. 18).

Medidas, em mm, or. Comprimento total, 30,0; comprimento do pronoto, 9,0; largura do pronoto, 15,0; comprimento da tégmina, 23,0; largura da tégmina, 12,0.

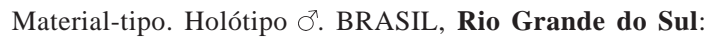
Encruzilhada do Sul ( $30^{\circ} 32$ ' 23 ', S, 52 19 ' $49^{\prime}$ 'W), 13.III.2003, A. L. Ruas Neto col. (MNRJ).

Etimologia: o nome da espécie é alusivo à Região Sul do Brasil, onde foi coletado o exemplar.

Diagnose: Blaptica sulina sp. nov. é similar a $B$. dubia, diferindo pela coloração do pronoto (figs. 7 , 12) e cabeça (figs. 1,6 ) e configuração do L2d (figs. 25 , $26,35,36)$.

Agradecimentos. À Dra. Janira Martins Costa (MNRJ) pelo apoio técnico. Ao Dr. Antonio Leite Ruas-Neto e equipe pelo material enviado para identificação.

\section{REFERÊNCIAS BIBLIOGRÁFICAS}

Hepper, H. C. 1965. Uma nueva espécie de Blaptica Stal de la Republica Argentina (Dictyoptera, Blaberidae, Blaberinae). Physis, 25(70):345-349.

Lopes, S. M. \& Oliveira, E. H. 2000. Espécie nova de Blaberus Serville, 1831 do Estado de São Paulo, Brasil (Blaberidae, Blaberinae). Boletim do Museu Nacional, nova série, Zoologia, 415:1-4.

McKitTRicK, F. A. 1964. Evolutionary studies of cockroaches. Cornell Experiment Station Memoir, 389:1-197.

Princis, K. 1963. Blattaria. In: BeIER, M. ed. Orthopterorum Catalogus. Pars 3, 4, 6, 7, 8, 11, 13, 14, Gravenhage, W. Junk. 1-1224p.

Rehn, J. A. G. \& Hebard, M. 1927. The Orthoptera of the West Indies. Number I. Blattidae. Bulletin of the American Museum of Natural History, 54:1-320.

Rотн, L. M. 1970. The male genitalia of Blattaria IV. Blaberidae: Blaberinae. Psyche, 77(2):217-236.

STÅL, C. 1875. Recherches sur le système des Blattaires. Bihang till Kongliga Svenska Vetenskaps-Akademiens, 2(13): $1-18$.

Recebido em outubro de 2004. Aceito em março de 2005. ISSN 0073-4721

Artigo disponível em: www.scielo.br/isz 